\title{
Medical Ethics in Extreme and Austere Environments
}

\author{
Christian S. Pingree ${ }^{1} \cdot$ Travis R. Newberry $^{1} \cdot$ K. Christopher McMains ${ }^{2}$. \\ G. Richard Holt ${ }^{3}$
}

Published online: 14 March 2020

(c) Springer Nature B.V. 2020

\begin{abstract}
American society has a history of turning to physicians during times of extreme need, from plagues in the past to recent outbreaks of communicable diseases. This public instinct comes from a deep seated trust in physician duty that has been earned over the centuries through dedicated and selfless care, often in the face of personal risks. As dangers facing our communities include terroristic events physicians must be adequately prepared to respond, both medically and ethically. While the ethical principles that govern physician behavior-beneficence, nonmaleficence, autonomy, and social justice - are unchanging, fundamental doctrines must change with the new risks inherent to terroristic events. Responding to mass casualty disasters caused by terrorists, natural calamities, and combat continue to be challenging frontiers in medicine. Preparing physicians to deal with the consequences of a terroristic disease must include understanding the ethical challenges that can occur.
\end{abstract}

Keywords Extreme environment · Disaster relief · Physician training · Combat ethics' military medical ethics

\section{Introduction}

The range of ethical dilemmas faced by clinicians in the usual care of their patients ranges from everyday ethical challenges to more difficult and serious dilemmas that may require a team approach, such as a clinical ethics consultation. Ethical dilemmas are generally addressed through the use of an analysis of issues and

G. Richard Holt

holtg@uthscsa.edu

1 Medical Corps, U.S. Air Force, Brooke Army Medical Center, Fort Sam Houston, San Antonio, Texas, USA

2 Medical Corps, U.S. Army Reserve, Audie Murphy VA Medical Center, San Antonio, Texas, USA

3 Professor Emeritus and Clinical Professor, U.T. Health Science Center at San Antonio, San Antonio, USA 
problem-solving process based on the ethical principles of autonomy, beneficence, non-maleficence, and social justice. Ethically acceptable options are considered, preferably in conjunction with the patient, the family, and/or a surrogate decisionmaker, with the resulting best ethical option agreed upon. This controlled process in a generally supportive environment is not always possible with ethical dilemmas that occur in austere environments, where decisions may be required without the opportunity to contemplate, consult, or discuss with patients or colleagues. In other words, the clinician must make a decision based on the information known at the time, and carry out the decided action in a timely manner under what could be dangerous or chaotic conditions.

These challenges describe the dilemmas often faced by clinicians who find themselves caring for patients during natural disasters, acts of terrorism, and combat, which by virtue of their circumstances, occur in threatening and stressful environments. These situations are not part and parcel of the usual medical education and training. While not every potential difficult situation can be predicted, understanding the potential general ethical challenges posed in austere environments before they might occur can better prepare a clinician with ethically permissible courses of action as a foundation. The following sections will develop the concepts of ethical challenges in civilian disasters and military combat and the importance of thoughtful preparation.

\section{Civilian Austere Environments}

The world health organization defines disaster as an "occurrence disrupting the normal conditions of existence and causing a level of suffering that exceeds the capacity of adjustment of the affected community" (WHO 2014). This can result from a large scale (flood or bombing) or a small scale (multiple-vehicle crash) event that overwhelms the local resources. Ethically and professionally, it is every physician's responsibility to patients and to society to understand the proper medical responses to a terroristic or mass casualty event in our community (Holt 2013). An impetus to improve physician preparation to effectively respond to civilian disasters followed in the wake of Hurricane Katrina in 2005. The loss of life, isolation of medical facilities to support, and the challenges of facing difficult ethical dilemmas caused by the disaster revealed the inadequacies of professional and institutional emergency medical preparation. Analyses of the range of preparation and coordination of emergency medical services led to enhanced organizational disaster training programs, as well as mandates for hospital systems to develop functionally responsive disaster response plans. It also became obvious that enhanced training for individual physician responses to civilian disaster, including ethical decision-making, was also required.

A number of organizations provide training for physicians in medical response for disaster events. The National Disaster Life Support Foundation (NFLSF) and the American Medical Association (AMA) have partnered in the development of courses in disaster life support. The courses range from basic to advanced training in triage, assessment, coordination with government relief programs, and the 
ethics of disaster medical care (https://www.ndlsf.org/all-courses). In a recent survey, nearly $90 \%$ of physician responders rated themselves as "fair-poor" in how to treat patients following biological events, public health emergencies, and terrorist attacks (Spranger et al. 2007). Those respondents who had previously taken the NFLSF training were statistically more likely to volunteer during one of these types of events. Approximately $80 \%$ of the surveyed physicians desired to acquire further training in proper medical responses.

The AMA's Code of Medical Ethics addresses physician preparation for disasters at national, regional, or local levels. Individually, physicians are encouraged to "take appropriate advance measures, including acquiring and maintaining appropriate knowledge and skills to ensure they are able to provide medical services when needed (https://www.ama-assn.org/delivering-care/physicians-responsibilities-disas terresponse-preparedness).

American society has a history of turning to physicians during times of extreme need, from plagues in the past to recent outbreaks of communicable diseases. This public instinct comes from a deep seated trust in physician duty that has been earned over the centuries through dedicated and selfless care, often in the face of personal risks. As dangers facing our communities include terroristic events physicians must be adequately prepared to respond, both medically and ethically. While the ethical principles that govern physician behavior-beneficence, non-maleficence, autonomy, and social justice - are unchanging, fundamental doctrines must change with the new risks inherent with terroristic events. Responding to mass casualty disasters caused by terrorists, natural calamities, and industrial accidents continue to be challenging frontiers in medicine. Preparing physicians to deal with the consequences of biologic and nuclear terroristic attacks must include understanding the ethical challenges that will undoubtedly accompany such disasters.

During 2016-2017, there were 991 documented terroristic attacks in the global terrorism database - of these, the majority were perpetrated with explosives and firearms (Global Terrorism Database 2014). One obstacle to the preparation for treating patients injured from terroristic attacks is the uncertainty that exists in the timing, location, and injuries sustained. Clauest et al. studied the frequency and severity of terroristic events and reported a "scale invariance" phenomenon; that is, the frequency of events is the inverse power of their severity (Clauset et al. 2007). That is, the larger the scale of the event, the less likely it is to occur. Conversely, there are smaller scale terrorist and natural disasters that have the potential to involve any physician at any location. Similar findings have been noted for natural disasters such as earthquakes, floods, and forest fires (Bak and Tang 1989; Malamud et al. 1998; Newman 2005).

The location of such crises may give rise to uncertainty in response efforts. School shootings, although not classic terrorist events, have arisen as new venues for loss of lives and multiple injured victims. Not only have the venues of terroristic events widened, but so have the scales of weapons utilized-consider the large scale bombings of Oklahoma City and the attacks on the World Trade Center. Recent attacks have also involved smaller scale devices, such as improvised explosive devices (IED) in Europe, and nerve gas exposure in London and Syria. In the 2014 Boston Marathon bombing and the 2017 Manchester Arena bombing, IEDs were 
used, which can create high-speed projectile secondary and tertiary injuries, which can be surgically challenging for responding medics and treating surgeons.

Our understanding of treating patients in terrorist events has, in good part, arisen from military experiences, but also from recent civilian tragedies. In response to the September 11, 2001 attacks on the World Trade Center, Saint Vincent Catholic Medical Center, the closest Level 1 trauma center to ground zero, activated detailed disaster plans within minutes, cancelling elective and outpatient services and clearing the emergency department in preparation for the expected wounded. Within minutes of the attacks they were prepared to treat the victims presenting to their emergency department in the immediate aftermath of the event. How were they able to do this so quickly? Their plans were informed by the prior World Trade Center bombing in 1993. Valuable lessons had been learned from prior experience in their hospital. However, despite their planning, they encountered significant communications and water-access logistical problems (Campbell 2002). Analyzing past efforts to respond to terroristic events, both successful and unsuccessful, inform our future preparations.

Although preparation needs to be planned on a hospital systems-wide level, individual physicians have important ethical considerations to consider. Physicians will face unique ethical considerations in their care of individual patient victims. How should physicians deal with injuries and needs outside their scope of practice in austere environments? What is the best approach from an ethical and legal standpoint to treatment of an unidentified victim? How can physicians assist families searching for their loved ones? What is the physician's role in treating a terrorist suspect? How does a physician prioritize clinical response management for a terroristic event, be it large- or small-scale? (Holt 2008)

In any austere environment, physicians may be called upon to expand their scope of practice to include life-saving and sustaining treatment for injuries and illnesses which have not necessarily been a part of their usual practice. This might result in an increased risk to victims. During Hurricane Katrina in New Orleans, LA, Dr. Anna Pou, a head and neck cancer surgeon, was one of a very few physicians who stayed on duty to care for patients at the Memorial Medical Center after the hurricane struck. She and other healthcare providers were faced with medication, oxygen supply and power shortages, among many other critical resources required for proper care (Pou 2013). This situation required an emergency expansion of her scope of practice at the hospital, not only in treating the seriously ill, but also in making triage decisions of the order of evacuation when rescue units arrived. The center of the multiple challenges in patient care under these adverse conditions was a large number of critically ill patients on a separate floor that was administered by an entity separate from Memorial Hospital. The physicians who cared for these long-term care patients, many of whom had "do not resuscitate" orders, were not at the hospital during the crisis. Most of the patients in this special unit were able to be evacuated, often by taking them to the roof of the hospital through a $3^{\prime} \times 3^{\prime}$ hole in the wall, by helicopter. Not all of the patients could be evacuated, and their health needs became critical when power was lost. Some patients were ventilator-dependent and required intermittent hand-ventilation. Some patients who were deemed to be suffering were given palliative support in the form of morphine and midazolam (Bailey 
2010). Some patients succumbed to a combination of their disease and the lack of appropriate ventilation, oxygen, and fluids. The physicians and nurses at Memorial Hospital during the hurricane crisis developed a triage system that reflected the austere environment under which the providers were required to make difficult patient care decisions. That unique crisis had not previously been experienced in recent times in the United States, with no specific training and guidelines that could have prepared the providers with protocols for their utilization.

Dr. Pou's honorable and professional actions during this crisis led to a national discussion to better prepare physicians and hospitals for responding to potential future crises, especially the need for reasonable expansion of practice scope, and protection, for physicians treating patients in austere environments. Her courage was supported by the AMA, the American Academy of Otolaryngology-Head and Neck Surgery, the American College of Surgeons, and the Louisiana State Medical Society. Extensive reflection and considerations of the implications for physician' participation in future disaster relief efforts, the state of Louisiana passed, in 2006, the Louisiana Health Emergency Powers Act, which provided the following exemption: "(c) During a state of public health emergency, any health care providers shall not be civilly liable for causing the death of, or, injury to, any person or damage to any property except in the event of gross negligence or willful misconduct" (Louisiana Health Emergency Powers Act 2006). Gross negligence and willful misconduct are also part of most "Good Samaritan Laws," and it is understood that any physician who voluntarily or involuntarily cares for victims of civilian disasters will adhere to the ethics and standards of care of the profession.

A number of additional issues have been raised following the Memorial Hospital responses to patient care under adverse conditions. For instance, should there be limits on an "expanded scope of practice" for health care providers in disaster situations? Dr. Pou is a head and neck surgeon and had experience in caring for post-surgical patients in the surgical intensive care unit. However, her training and experience were limited in caring for patients with multiple and serious medical comorbidities. Had there been present critical care physicians at Memorial, would the outcomes have been different? Possibly so. Conversely, should critical care physicians be expected to perform life-saving surgical procedures for which they are not trained or knowledgeable? Likely not. Thus, some common sense limitations on expanded scope of practice would be appropriate as an ethical responsibility.

Another important issue for a priori consideration is that of an equitable and appropriate triage protocol for patients who are considered to be "expectant" or have a "do not resuscitate" order in place. The military triage model might fit for a limited disaster or terrorist event, but was not a good fit for the Memorial situation where transportation/evacuation was cut off for a period of time, and the normal hospital systems failed during the flooding. It is likely that no subsequent disasters will produce the exact same conditions as Hurricane Katrina for a health care facility and providers, but in the civilian setting these lessons should lead to improved and responsive hospital protocols for triage, resuscitation, personnel staffing for imminent disasters, palliative care (when and how much), and ongoing health care provider training and simulations. The input from a health care ethicist can provide the ethical perspective for disaster relief plans and protocols and should be a constant 
element for all institutions. Specialty specific considerations, including ethical behavior, should be coordinated with larger medical society guidelines (American Medical Association, American College of Surgeons) for uniformity of process and concepts.

Identifying the challenges faced by the medical and nursing staffs at Memorial Hospital during Hurricane Katrina, as well as other medical facilities in the New Orleans area, raised national awareness and resulted in enhanced educational programs and training for future disaster responses. Longitudinal improvements in institutional and organizational response planning continues as additional experience is gained from other national disasters in which ethical challenges are identified and reviewed.

\section{Terrorist Events}

While treating victims of terroristic attacks can be quite challenging, how does a physician approach the care of the perpetrators? Are there limits to the ethical treatment of humans who allegedly have committed such violence? In their thought-provoking article, Gesundheit et al. related the difficult feelings these Israeli physicians felt when treating Hamas fighters who had been captured in acts of violence and terrorism. They asked, among other questions, "Should hospitals expend limited public health care resources on a terrorist, thereby perhaps depriving other patients of medical care?" (Gesundheit et al. 2009a). From a legal perspective, Gesundheit and other responders to this article point out that terrorist suspects are not covered under the "Geneva Convention Relative to the Treatment of Prisoners of War" definition of "lawful combatants". Their activity should therefore be treated as illegal acts of civilians. The Geneva Convention relative to the Protection of Civilian Persons in Time of War states that the wounded, whether "members of armed forces who have laid down their arms" or "those placed out of action by sickness, wounds, detention, or any other cause," should still be treated "humanely, without any adverse distinction founded on race, color, religion, or faith, sex, birth or wealth, or any other similar criteria". "Their (the suspected terrorist's) use of illegal war methods does not justify violations of those rules by the other side... Terrorism is no different than any other willful acts committed during war and does not justify an exception to the physician's obligation to treat" (Geneva Convention (IV) 1949; Davis 2009; Marks 2009; Lepora et al. 2009).

But where does a physician's commitment to the ethical principle of social justice fit into this scenario of caring for a suspected terrorist? Physicians do have an ethical responsibility to promote justice in care, but that responsibility is to social justice and not punitive justice (Brassington 2009). When a patient who is suspected of terroristic, or any other illegal activity, is under a physician's emergency care, they must be treated as though they were only allegedly guilty and not as though they were convicted. Social justice should protect against discrimination on nonmedical grounds (including suspected terrorist activity, or which ideology the patient follows) (Davis 2009). It is the ethical responsibility of the physician and the healthcare team to care for those when and where they can, even if the suspected 
terrorists have just committed atrocities aimed at the physician's community. There will likely be emotional conflicts within the health care team, but as Gesunheit and colleagues described, it is possible to control those conflicts under the guidelines of a physician's ethical responsibility. From both a legal and ethical perspective, there is a responsibility to treat terroristic suspects only according to their injury acuity, regardless of the emotional conflicts (Gesundheit et al. 2009b). However, it may be "easier stated, than done."

The AMA's Code on Medical Ethics on physician disaster response and preparedness explicitly states that "Because of their commitment to care for the sick and injured, individual physicians have an obligation to provide urgent medical care during disasters. This obligation holds even in the face of greater than usual risks to physicians' own safety, health, or life. However, the physician workforce is not an unlimited resource. Therefore, when providing care in a disaster with its inherent dangers, physicians also have an obligation to evaluate the risks of providing care to individual patients versus the need to be available to provide care in the future" (https://www.ama-assn.org/delivering-care/physicians-responsibilities-disasterresponse-preparedness).

Physicians cannot be available to care for victims if they become casualties themselves; therefore, physicians should be cognizant of the importance of their own safety and that of their healthcare team, as well as the safety of their patients. This premise is based on the social worth that a physician can provide to society over the course of a practice lifetime (Gesundheit et al. 2009b). However, this instinct of selfprotection should be carefully weighed and considered by each physician so as to avoid abandoning professional responsibilities to patients in the name of self-preservation. Personal protective equipment and treatment should be available to first responders and subsequent care providers who will be treating the injured to ensure that they are able to continue caring for patients. Triage, therefore, is considered a nuanced combination of medical/surgical priorities and the preservation of first responder and physician capabilities over the course of the treatment period.

\section{Military Extreme Environments}

Physicians who provide medical and surgical care as members of any nation's Armed Forces face the task of preparing to practice in multiple settings, often austere and extreme. Outside of combat, these settings and issues are, for the most part, similar to civilian practice. In the extreme environment of combat, circumstances may arise that create tension on the sworn responsibilities of physician and officer. Military physicians serve two primary roles-physician and officer. As physicians, their role is to engage in the care of patients according to established ethical guidelines. As military officers, their role is to "support and defend the constitution against all enemies". Much is made of the "dual agency" of the military medical officer with respect to duties and responsibilities to the patient as well as the military unit. It is worth noting that this "dual agency" is not unique to the military. Physicians working as employees will have contractual obligations and limitations that range from fairly benign (e.g., restricting prescribing medications that are "on 
the formulary") to morally tenuous (e.g., hospital systems denying care primarily due to cost considerations). The significant difference between these situations and those encountered by the military physician is that, in the military setting, additional legal frameworks and international laws apply. For military physicians worldwide, these include the Geneva Conventions (Cross 2014), the Declaration of Helsinki (World Medical Association 2017), the International Code of Medical Ethics (World Medical Association 2014), Regulations in Times of Armed Conflict (World Medical Association 2016), and the Declaration of Tokyo (World Medical Association 2006). For US Military officers, this also includes the Uniform Code of Military Justice (https://uscode.house.gov/view.xhtml?path=/prelim@ title10/subtitleA/part2/ chapter47\&edition=prelim).

The US Army Field Manual 1 (FM1) states, "The purpose of any profession is to serve society by effectively delivering a necessary and specialized service." It continues, "Each profession establishes a unique subculture that distinguishes practitioners from the society they serve while supporting and enhancing that society." Finally, "Professions create their own standards of performance and codes of ethics to maintain their effectiveness" (US, Department Army 2005). Arguments for the legitimacy of professional armed forces base their claims on theories of "just war". These include justification for going to war (jus ad bellum) and moral conduct of war itself (jus in bello) (Guthrie and Quinlan 2007). Medical personnel in this role have an obligation both to the standards of the medical and martial professions. To the extent that these are in tension, that tension must be resolved on the side of medical ethics. An example of this is the standard of confidentiality. In civilian practice, there is a "duty to notify" appropriate authorities if a patient is a danger to self or others. In the military context, that duty also extends to those patients who present a threat to mission. In such cases, the "minimal necessary" standard is applied, wherein the physician reveals only the minimum necessary information to the commander for him/her to assess and address the situation. In all situations, the military physician is physician first and officer second.

Commanders require pertinent information from their medical officers that enable them to make appropriate decisions regarding operational planning, including the disposition of individual military personnel. Typically, this will involve a "ready" or "not ready" recommendation on deployment status or return to duty. Commanders normally honor the medical officer's recommendations, although operational requirements may require that the commander over-ride medical advice. If the medical officer further disagrees, then she/he can strongly reaffirm the recommendation for medical and ethical reasons, and understand their obligation to the service-member patient is in delicate balance with the operational needs of the military and the commander's decision. Each case must be handled on its own merits, and the medical officer must guard personal health information that is not critical to the mission, but might be prejudicial against the service-member.

Placement of medical personnel is a continued source of interest and discussion. Data strongly support benefits of early transport and resuscitation of combat wounded (Kotwal et al. 2016). Medical personnel have an obligation to advocate for implementation of practices that may improve patient outcomes, and arguments can be made to place physicians close-to or on the battlefield. However, medical assets 
located close to combatant units may receive accidental fire. Thus, locating medical assets close to combat units decreases the time from injury to treatment, but carries additional risk to medical personnel, installation, and supplies.

On the battlefield, first responders serve, in large part, to treat coalition forces. No care is provided to combatant forces until they "indicate surrender, drop all weapons, and is proven to no longer pose a threat". Combat medics provide critical services as first responders and are afforded non-combatant status assuming they identify themselves as medical personnel, respect principles of medical ethics, and provide care to all victims without discrimination. Combat medics may bear arms to protect themselves or their patients but they give up the right of non-combatant status if they undertake non-medical functions during an armed conflict. This situation may occur, for example, in special forces units when the medic is also expected to perform additional non-medical combat functions.

During armed conflict, physicians must treat soldiers not "as discrete patients, but as components of a fighting force, a living collective entity" (United States. Office of the Surgeon General United States Army 2013). The objective of such treatment is the "return of the greatest possible number of warfighters to combat and the preservation of life, limb and eyesight" (Emergency War Surgery). Often times, there is an overwhelming demand for limited medical resources and the need to prioritize care of the sick and injured. Within the US Armed Forces, the triage system categorizes patients into Immediate (requiring surgery with 2 hours), Delayed (requiring surgery, but in stable condition allowing others to receive treatment first), minimal (minor injuries requiring little medical care), and Expectant (non-survivable injuries) (Warner et al. 2011). In military mass casualty situations, expectant patients are attended and given comfort measures, though the limited medical resources are conserved for those with survivable injuries. This situation places the principles of beneficence (potential good for the individual patient) in tension with justice (equal care and resources for all patients). Ultimately, this decision is justified by utilitarian analysis, doing the greatest good, not for individual patients but for the aggregate fighting force.

The triage of enemy combatants poses an additional ethical dilemma. While still actively pursuing acts of war, medical personnel have no obligation to care for the enemy. Once an enemy can no longer take part in hostilities (e.g., becoming too badly injured or sick, or becoming a POW), the military medical services have a duty to care for these individuals. Moreover, Article 12 of the Geneva Conventions states that only "urgent medical reasons" will inform the order in which care is administered (International Committee of the Red Cross 2014). Care must be administered "without any adverse distinction founded on race, color, religion or faith, sex, birth or wealth, or any other similar criteria." Although such treatment may generate an emotional response from combatants and medical personnel alike, commitment to treating enemy wounded upholds both the ethical principles of beneficence and justice. It also reinforces a standard of treatment for injured friendly forces. The issue of informed consent deserves specific mention. It can be argued that a detained enemy cannot give truly informed consent given that he/she remains subject to coercion. Military medical personnel must include due consideration of the principle of autonomy in such situations. 
There are times when the triage of patients may be delayed to protect medical assets including medical personnel. For example, personnel who have been contaminated by radiation, biological or chemical weapons must be decontaminated prior to entering a medical facility. They may also receive pre-hospital care in this setting. This should be completed by medical personnel who are appropriately trained, equipped, and protected. This arrangement seeks to neutralize the effects of the involved agents and begin treatment of the afflicted, while preserving the ability of fixed medical installations to render care.

In extreme situations, non-combatants are permitted to defend themselves and their patients if attacked by an enemy force. When medical personnel take up offensive arms (not in self-defense), they lose the protections of international law. Additionally, they jeopardize those in their care. In regards to patient abandonment in combat situations, Article 12 of Convention I states that when "compelled to abandon wounded or sick to the enemy shall, as far as military considerations permit, leave with them a part of its medical personnel and material to assist in their care" (World Medical Association 2016). This suggests extreme circumstances when multiple considerations might prevail upon medical personnel to leave patients entrusted to their care.

In the above discussion, it is clear that many ethical considerations face the military physician beyond those of conventional civilian practice. Formal training programs have demonstrated significant improvement in ethical understanding and behaviors among combat troops. It is also clear that human performance and decision-making erodes under acute stress. This background and the low likelihood that military physicians would encounter these dilemmas outside of the combat setting underscores the importance of training in and consideration of these scenarios prior to service in combat. In its Subcommittee report entitled "Ethical Guidelines and Practices for US Military Medical Professionals", the Defense Health Board found that, "a priori education and training provide the best strategies for providing military health care professionals with the skills, experience, and knowledge they can draw on when confronting difficult ethical choices" (Defense Health Board 2015). Participation in actions that conflict with ethical standards of medical practice can cause moral injury to the physician who bears dual agency. Recognition of this very real harm mandates deliberate preparation and training of the military physician prior to entering the theater of conflict as well as adequate support to her/him while executing those duties.

\section{Conclusion}

Ethical issues and challenges are part and parcel of the practice of medicine. Every physician faces ethical decisions in clinical patient care, analyzing the options based on the ethical principles of autonomy, beneficence, non-maleficence, and social justice, and selecting the best ethical option, usually in conjunction with the patient (shared decision-making). However, unique ethical challenges for physicians present during civilian disease and military combat situations that are often specific to the 
austere environments in which they occur. These challenges can require physicians to make decisions that are outside the usual parameters of clinical practice.

While most physicians may never find themselves in these unique environments, recent history has demonstrated that natural disasters and terrorist attacks can occur without warning, anywhere in the United States, which emphasizes the importance for physician preparation and training. The ethical challenges for a physician may also be prepared for through an understanding of the difficult decisions likely to be faced in caring for patients in a disaster situation. Individual physician training in basic and advanced disaster life support, which includes ethical decision-making, is an excellent preparation. It is hoped this introduction to ethical challenges involved in patient care during civilian disasters and military combat will stimulate the reader to engage further with the topics.

Author Contributions The statements and opinions expressed in the articles and communications herein are those of the author(s) and not necessarily those of the U.S. Army, U.S. Air Force, the Department of Defense, or the University of Texas Health Science Center at San Antonio.

\section{References}

AMA. (2018). Code of Medical Ethics Opinion 8.3. Physicians' responsibilities in disaster response \& preparedness. Retrieved May 14, 2019, from https://www.ama-assn.org/delivering-care/physicians -responsibilities-disaster-response-preparedness.

Bailey, R. (2010). The case of Dr. Anna Pou: Physician liability in emergency situations. Virtual Mentor, 12(9), 726-730.

Bak, P., \& Tang, C. (1989). Earthquakes as a self-organized critical phenomenon. Journal of Geophysical Research: Solid Earth, 94(B11), 15635-15637.

Brassington, I. (2009). Separating the 'rights of' and 'justice for 'bombers. The American Journal of Bioethics, 9(10), 59-61.

Campbell, D. J. (2002). 9/11: A healthcare provider's response. Frontiers of Health Services Management, $19(1), 3$.

Clauset, A., Young, M., \& Gleditsch, K. S. (2007). On the frequency of severe terrorist events. Journal of Conflict Resolution, 51(1), 58-87.

Davis, M. (2009). Terrorists are just patients. The American Journal of Bioethics, 9(10), 56-57.

Defense Health Board. (2015). Ethical guidelines and practices for US military medical professionals. Office of the Assistant Secretary of Defense for Health Affairs. Falls Church, VA. Retrieved November 4, 2018, from https://apps.dtic.mil/dtic/tr/fulltext/u2/1027321.pdf.

Geneva Convention (IV). (1949). Relative to the protection of civilian persons in time of war. Retrieved August 12, 2019, from https://www1.umn.edu/humanrts/instree/1949f.htm.

Gesundheit, B., Ash, N., Blazer, S., \& Rivkind, A. I. (2009a). Medical care for terrorists-to treat or not to treat? The American Journal of Bioethics, 9(10), 40-42.

Gesundheit, B., Ash, N., Blazer, S., \& Rivkind, A. I. (2009b). Medical care for terrorists-yes to treat! The American Journal of Bioethics, 9(10), W3-W4.

Global Terrorism Database. (2014). Definitions: Emergencies. Retrieved November 17, 2019, from https ://www.who.int/hac/about/definitions/en/.

Guthrie, C., \& Quinlan, M. (2007). Just War: The just war tradition : Ethics in modern warfare. New York: Walker \& Co.

Holt, G. R. (2008). Making difficult ethical decisions in patient care during natural disasters and other mass casualty events. Otolaryngology_Head and Neck Surgery, 139(2), 181-186.

Holt, G. R. (2013). A physician's ethical responsibility to prepare for and respond to disasters and other catastrophic events. Southern Medical Journal, 106(1), 1-2. 
International Committee of the Red Cross. (2014) Geneva Conventions. [online]. Retrieved August 12, 2018, from https://www.icrc.org/en/war-and-law/treaties-customary-law/geneva-conventions.

Kotwal, R. S., et al. (2016). The effect of a golden hour policy on the morbidity and mortality of combat casualties. JAMA Surgery, 151(1), 15-24.

Lepora, C., Danis, M., \& Wertheimer, A. (2009). No exceptionalism needed to treat terrorists. The American Journal of Bioethics, 9(10), 53-54.

Louisiana Health Emergency Powers Act. (2006). RS 29: Section 771. Retrieved February 20, 2020, from https://law.justia.com/codes/louisiana/2006/13/207689.html.

Malamud, B. D., Morein, G., \& Turcotte, D. L. (1998). Forest fires: An example of self-organized critical behavior. Science, 281(5384), 1840-1842.

Marks, J. H. (2009). The terrorist and the doctor: A legal and ethical response. The American Journal of Bioethics, 9(10), 49-51.

National Disaster Life Support Foundation Courses. Retrieved January 18, 2019, from https://www.ndlsf .org/all-courses.

Newman, M. E. (2005). Power laws, Pareto distributions and Zipf's law. Contemporary Physics, 46(5), 323-351.

Pesik, N., Keim, M. E., \& Iserson, K. V. (2001). Terrorism and the ethics of emergency medical care. Annals of Emergency Medicine, 37(6), 642-646.

Pou, A. M. (2013). Ethical and legal challenges in disaster medicine: Are you ready? Southern Medical Journal, 106, 27-30. https://doi.org/10.1097/SMJ.0b013e31827ca40c.

Spranger, C. B., Villegas, D., Kazda, M. J., Harris, A. M., Mathew, S., \& Migala, W. (2007). Assessment of physician preparedness and response capacity to bioterrorism or other public health emergency events in a major metropolitan area. Disaster Management \& Response, 5(3), 82-86.

US, Department of the Army. (2005). FM 1: The army. Washington, DC: Government Printing Office. Retrived November 4, 2018, from https://www.globalsecurity.org/military/library/policy/army/fm/1/ fm1_2005.pdf.

Uniform Code of Military Justice (UCMJ). (2019). 10 U.S.C. $\S \S 886,921$. Retrived November 2, 2018, from https://uscode.house.gov/view.xhtml?path=/prelim@title10/subtitleA/part2/chapter47\&editi on=prelim.

United States. Office of the Surgeon General United States Army. (2013). Emergency war surgery (4th US revision). Borden Institute: Ft. Sam Houston, Texas. Retrieved November 4, 2018, from https:// www.cs.amedd.army.mil/borden/.

WHO. (2014). Definitions: Emergencies. Retrived November 2, 2018, from https://www.who.int/hac/ about/definitions/en/.

Warner, C. H., et al. (2011). Effectiveness of battlefield-ethics training during combat deployment: A programme assessment. Lancet, 378(9794), 915-924.

World Medical Association. (2017). Declaration of Helsinki. Retrieved August 14, 2018, from https:// www.wma.net/policies-post/wma-declaration-of-geneva.

World Medical Association. (2014). International code of medical ethics. Retrieved August 14, 2018, from https://www.wma.net/policies-post/wma-international-code-of-medical-ethics/.

World Medical Association. (2016). Ethical principles of health care in times of armed conflict and other emergencies. Retrieved August 14, 2018, from https://www.wma.net/wpcontent/uploa ds/2017/02/4245_002_Ethical_principles_web.pdf.

World Medical Association. (2006). WMA Declaration of Tokyo-guidelines for physicians concerning torture and other cruel, inhuman or degrading treatment or punishment in relation to detention and imprisonment. Retrieved August 14, 2018, from https://www.wma.net/policies-post/wma-declaratio n-of-tokyo-guidelines-for-physicians-concerning-torture-and-other-cruel-inhuman-or-degradingtreatment-or-punishment-in-relation-to-detention-and-imprisonment/.

Publisher's Note Springer Nature remains neutral with regard to jurisdictional claims in published maps and institutional affiliations. 